\title{
Selective Defect in Myeloid Cell Lactoferrin Gene Expression in Neutrophil Specific Granule Deficiency
}

\author{
Karen J. Lomax, “ John I. Gallin,“ Daniel Rotrosen,“ Gordon D. Raphael," Michael A. Kaliner, ${ }^{\star}$ Edward J. Benz, Jr., \\ Laurence A. Boxer," and Harry L. Malech* \\ *Bacterial Diseases Section and Allergic Diseases Section, Laboratory of Clinical Investigation, National Institute of Allergy and \\ Infectious Diseases, National Institutes of Health, Bethesda, Maryland 20892; ${ }^{\ddagger}$ Department of Medicine, Yale University, \\ New Haven, Connecticut 06510; and ${ }^{\S}$ Department of Pediatrics, University of Michigan, Ann Arbor, Michigan 48109
}

\begin{abstract}
Neutrophil specific granule deficiency (SGD) is a congenital disorder associated with an impaired inflammatory response and a deficiency of several granule proteins. The underlying abnormality causing the deficiencies is unknown. We examined mRNA transcription and protein synthesis of two neutrophil granule proteins, lactoferrin and myeloperoxidase in SGD. Metabolically labeled SGD nucleated marrow cells produced normal amounts of myeloperoxidase, but there was no detectable synthesis of lactoferrin. Transcripts of the expected size for lactoferrin were detectable in the nucleated marrow cells of two SGD patients, but were markedly diminished in abundance when compared with normal nucleated marrow cell RNA. Because lactoferrin is secreted by the glandular epithelia of several tissues, we also assessed lactoferrin in the nasal secretions of one SGD patient by ELISA and immunoblotting. Nasal secretory lactoferrin was the same molecular weight as neutrophil lactoferrin and was secreted in normal amounts. From these data, we conclude that lactoferrin deficiency in SGD neutrophils is tissue specific and is secondary to an abnormality of RNA production. We speculate that the deficiency of several granule proteins is due to a common defect in regulation of transcription that is responsible for the abnormal myeloid differentiation seen in SGD patients.
\end{abstract}

\section{Introduction}

Neutrophil specific granule deficiency (SGD) ${ }^{1}$ is a rare congenital disorder that is characterized by recurrent infections of skin and deep tissues with a variety of bacterial and fungal pathogens without any increased propensity for viral infection (1). Morphological examination of neutrophils from these patients reveals absent specific or secondary granules on Wright's stain and multiple nuclear abnormalities including blebs, clefts, and bilobed nuclei. In vitro functional disturbances of receptor upregulation, chemotaxis, bactericidal activity, and disaggregation have also been described in SGD neutrophils (2).

Address reprint requests to Dr. Karen J. Lomax, Bacterial Diseases Section, LCI, National Institute of Allergy and Infectious Diseases, National Institutes of Health, Building 10, Room 11N112, Bethesda, MD 20892.

Received for publication 27 June 1988 and in revised form 7 September 1988 .

1. Abbreviations used in this paper: SGD, specific granule deficiency.

The Journal of Clinical Investigation, Inc.

Volume 83, February 1989, 514-519
After subcellular fractionation of the granule components of SGD neutrophils on a sucrose gradient, the primary granule fraction is seen as a single broad band that is less dense than normal and the band of the expected density for specific granules is absent (3-5). These abnormal banding patterns are associated with the absence or deficiency of a subset of neutrophil secretory proteins that may not be limited to those usually found in specific granules such as lactoferrin and vitamin B-12-binding protein. Other granule proteins, such as the primary granule protein, defensin (6), and the tertiary granule protein, gelatinase $(2,7)$ are also deficient. However, not all neutrophil granule proteins are affected and some, such as myeloperoxidase, are present in normal amounts in these patients. The molecular defect responsible for the abnormalities described in SGD neutrophils has not been defined. Because the deficiencies seen in SGD neutrophils involve several secretory proteins from different granule compartments, it is likely that the primary defect is one of regulation of production of these proteins, rather than a mutation of each gene coding for a deficient protein.

We studied production of one deficient granule protein, lactoferrin, in both myeloid and nonmyeloid tissues to begin to define the molecular basis of SGD. Our results demonstrate that there is a myeloid cell-specific defect in synthesis of lactoferrin at the transcriptional level. These data support our hypothesis that the granule protein deficiencies in SGD may represent an abnormality of regulation of protein production and are not secondary to mutations in multiple genes.

\section{Methods}

Bone marrow aspirates. Informed consent according to approved protocols was obtained from all patients from whom tissue specimens were obtained. Bone marrow aspirates collected in heparin were obtained from the posterior iliac crests of two patients with SGD who have been described previously $(8,9)$ and two healthy individuals. Differential cell counts on Wright-Giemsa-stained slides were as follows: Patient M.F., promyelocytes $4 \%$, myelocytes/metamyelocytes $57 \%$, segmented neutrophils/bands $15 \%$, lymphocytes $1 \%$, plasma cells $1 \%$, and erythrocytic elements $22 \%$. Patient M.S., promyelocytes $0 \%$, myelocytes/metamyelocytes $40 \%$, segmented neutrophils/bands $9 \%$, lymphocytes $21 \%$, plasma cells $3 \%$, and erythrocytic elements $27 \%$. Normal individual 1, promyelocytes $0 \%$, myelocytes/metamyelocytes $37 \%$, segmented neutrophils/bands $18 \%$, lymphocytes $15 \%$, and erythrocytic elements $30 \%$. Normal individual 2, promyelocytes $1 \%$, myelocytes/metamyelocytes $20 \%$, segmented neutrophils $31 \%$, eosinophils $3 \%$, lymphocytes $24 \%$, and erythrocytic elements $21 \%$. Nucleated marrow cells were isolated by dextran sedimentation followed by hypotonic lysis of erythrocytes. A decrease in segmented neutrophils and bands relative to earlier myeloid precursors is noted in patient M.S., and is probably due to ongoing chronic infection in this patient.

Northern blot analysis. Total cellular RNA was prepared from nucleated marrow cells isolated as above by the method of Chirgwin (10) 
or by centrifugation through a cesium chloride gradient after lysis in guanidinium isothiocyanate (Fluka Chemical Corp., Ronkonkoma, NY).

Peripheral blood leukocytes were obtained from a patient with chronic myelogenous leukemia via leukapheresis. Granulocyte precursors were isolated with the monocyte layer by Ficoll-Hypaque centrifugation. Differential cell count from a Wright-Giemsa-stained slide of the cell layer containing monocytes and myeloid precursors was as follows: myeloblasts $8 \%$, myelocytes/metamyelocytes $38 \%$, bands $5 \%$, neutrophils $1 \%$, monocytes $20 \%$, and lymphocytes $28 \%$. Cells were lysed in guanidinium isothiocyanate and centrifuged through a cesium chloride gradient to isolate total cellular RNA.

Uninduced HL-60 cells, a human promyelocytic cell line (11), were harvested from culture in RPMI and 10\% FCS and total cellular RNA was prepared as described above. Fresh nasal turbinate tissue from patients undergoing therapeutic turbinectomy was homogenized in guanidinium isothiocyanate and particulate matter was removed with low speed centrifugation. Supernatants were spun through a cesuim chloride gradient to isolate RNA.

RNA samples were electrophoresed through $1.8 \%$ agarose-formaldehyde gels and blotted onto a membrane (Nytran; Schleicher \& Schuell, Keene, NH) overnight in $20 \times \mathrm{SSC}(1 \times \mathrm{SSC}=150 \mathrm{mM} \mathrm{NaCl}$, $15 \mathrm{mM}$ Na citrate, $\mathrm{pH} 7.0$ ). The blots were hybridized in $50 \%$ formamide, $5 \times \operatorname{SSPE}\left(1 \times \mathrm{SSPE}=180 \mathrm{mM} \mathrm{NaCl}, 10 \mathrm{mM} \mathrm{NaPO}_{4}(\mathrm{pH} 7.7)\right.$ 1 mM EDTA), $0.1 \%$ SDS, $5 \times$ Denhardt's solution ( $1 \times$ Denhardt's $=0.02 \%$ Ficoll, $0.02 \%$ polyvinylpyrrolidone, $0.02 \% \mathrm{BSA}$ ), and 100 $\mu \mathrm{g} / \mathrm{ml}$ heterologous DNA for $12-18$ hs. Hybridization probes were either a nick-translated plasmid containing $\sim 1 \mathrm{~kb}$ of lactoferrin cDNA (12) or a nick-translated 2.2-kb fragment of myeloperoxidase cDNA (13). Blots were washed in a final solution of $0.1 \times$ SSC, $0.1 \%$ SDS at $55^{\circ} \mathrm{C}$ and autoradiographed at $-80^{\circ} \mathrm{C}$ with intensifying screens.

Southern blot analysis. $10 \mu \mathrm{g}$ of genomic DNA isolated from peripheral leukocytes were digested with restriction endonucleases and run on a $1 \%$ agarose gel. Gels were blotted onto a membrane (Nytran) overnight in 10× SSC. Blots were hybridized overnight in 50\% formamide, $6 \times$ SSPE, $1 \%$ SDS, $5 \%$ dextran, $50 \mu \mathrm{g} / \mathrm{ml}$ heterologous DNA with nick-translated plasmid probe containing $\sim 1 \mathrm{~kb}$ of lactoferrin cDNA. Final washes were in $0.1 \times \mathrm{SSC}, 0.1 \%$ SDS at $55^{\circ} \mathrm{C}$. Blots were autoradiographed at $-80^{\circ} \mathrm{C}$ for $72 \mathrm{~h}$.

Bone marrow protein immunoprecipitation. $20 \times 10^{6}$ nucleated marrow cells isolated as described above from patient M.S. and a healthy donor were incubated for $4 \mathrm{~h}$ at $37^{\circ} \mathrm{C}$ in RPMI without methionine, $10 \% \mathrm{FCS}$, and $1 \mathrm{mCi}$ of $\left[{ }^{35} \mathrm{~S}\right]$ methionine. This was followed by an ice-cold chase of RPMI with $10 \mathrm{mM}$ cold methionine. Labeled cells were stored frozen at $-80^{\circ} \mathrm{C}$.

Metabolically labeled nucleated marrow cells were solubilized in PBS containing 1\% SDS, $1 \mathrm{mM}$ EDTA, and protease inhibitors and sheared through a 21 -gauge needle. After centrifugation at $12,000 \mathrm{~g}$ in a microcentrifuge, the supernate was collected and Triton X-100 was added to achieve a concentration of $2 \%$ Triton X-100. Protein Acoated Staphylococcus (Pansorbin; Calbiochem-Behring Corp., La Jolla, CA) was added to the supernate and then removed by centrifugation to remove nonspecifically bound material. The supernate was then reacted with either rabbit antihuman lactoferrin (Cappel Laboratories-Worthington Biochemicals, Malvern, PA) or antimyeloperoxidase (14) and immunoprecipitated with Pansorbin. These reactions were also carried out in the presence of excess amounts of exogenously added pure lactoferrin or myeloperoxidase for competitive binding as appropriate. Samples were mixed with $6 \%$ SDS sample buffer and analyzed on a $10 \%$ acrylamide gel followed by staining with $0.05 \%$ Coomassie brilliant blue and autoradiography.

Nasal provocation and ELISA. Samples of nasal secretions were obtained from SGD patient M.S. on two occasions. On the first occasion, only an unstimulated unilateral nasal lavage was performed. On the second occasion, bilateral baseline collections were obtained first, and then an oral gustatory challenge was performed in both the patient and a normal individual. Subjects were seated in an upright position and soft $8 \mathrm{~F}$ rubber catheters were atraumatically inserted along the floors of one or both nasal cavities to collect nasal secretions and lavages. Nasal saline was delivered to the nose from a hand-held nebulizer bottle and collected by suction through the catheters. Each nasal cavity was lavaged with a 4-ml saline prewash, and then subjects were asked to ingest slowly one or two hot chili peppers to stimulate nasal glandular secretion. After this 10-min oral challenge, the nasal cavities were again lavaged with $4 \mathrm{ml}$ of saline and the fluid collected was assayed for total protein and lactoferrin.

Total protein was measured by the Lowry method using BSA as the standard (15). Lactoferrin was measured by a direct, noncompetitive ELISA. Microtiter plates were coated with rabbit antihuman lactoferrin (Dako Corp., Santa Barbara, CA) and then blocked with $1 \%$ goat serum diluted in a phosphate buffer (16). Unknown samples or lactoferrin standards were then added, and this was followed by the addition of a rabbit antihuman lactoferrin-horseradish peroxidase conjugate (Cappel Laboratories-Worthington Biochemicals). The plates were developed with a peroxidase substrate (o-phenylenediamine dihydrochloride) and read at $490 \mathrm{~nm}$. The assay sensitivity is $1 \mathrm{ng} / \mathrm{ml}$.

$S D S-P A G E$ and immunoblotting. Peripheral blood neutrophils were suspended in $\mathrm{Ca}^{2+}, \mathrm{Mg}^{2+}$-free HBSS supplemented with $3 \mathrm{mM}$ diisopropylfluorophosphate (30-60 $\mathrm{min})$ and washed. Cell pellets (2.5 $\times 10^{6}$ cells) or $0.1-\mathrm{ml}$ aliquots of resting and stimulated nasal secretions were solubilized for SDS-PAGE, heated at $100^{\circ} \mathrm{C}$ for $2 \mathrm{~min}$, and analyzed on $10 \%$ polyacrylamide slab gels. Red blood cell membrane ghosts were used as molecular weight markers (17). Proteins were transferred to nitrocellulose paper $(40 \mathrm{~V} \times 18 \mathrm{~h}$, in $25 \mathrm{mM}$ Tris, $\mathrm{pH}$ $8.3,192 \mathrm{mM}$ glycine, $20 \%$ methanol) and stained with fast green (Sigma Chemical Co., St. Louis, MO). Positions of molecular weight standards were marked and fast green was eluted from the blots during blocking in 5\% nonfat dry milk in Tris-buffered saline. The transferred proteins were probed with rabbit antihuman lactoferrin (Cappel Laboratories-Worthington Biochemicals) 1:250 dilution in Tris-buffered saline supplemented with $1 \%$ gelatin, followed by peroxidase-conjugated goat anti-rabbit IgG (Kirkegaard and Perry Laboratories, Inc., Gaithersburg, MD), 1:300 dilution, and developed with 4-chloronaphthol as described (18).

\section{Results}

Lactoferrin and myeloperoxidase protein synthesis by nucleated marrow cells. The same number of nucleated marrow cells from a normal volunteer and from SGD patient M.S. were metabolically labeled with $\left[{ }^{35} \mathrm{~S}\right]$ methionine, detergent solubilized and subjected to immunoprecipitation with either antilactoferrin or antimyeloperoxidase, with or without excess cold lactoferrin or myeloperoxidase. Immunoprecipitates were analyzed by SDS-PAGE and autoradiography. Results of this analysis are shown for a normal individual and for patient M.S. in Figs. 1 and 2, respectively.

Antilactoferrin precipitated a radiolabeled band of $79 \mathrm{kD}$ from normal nucleated marrow cells that was not precipitated when excess cold lactoferrin was added before immunoprecipitation (Fig. 1, lanes $A$ and $B$ ). This pattern is identical to that previously reported for metabolically labeled lactoferrin from normal nucleated marrow cells (19). Antilactoferrin did not precipitate any radiolabeled material corresponding to lactoferrin from patient M.S. nucleated marrow cells (Fig. 2, lanes $A$ and $B$ ). Even with a prolonged autoradiographic exposure, there was no lactoferrin band detectable from patient M.S. nucleated marrow cells (not shown).

Antimyeloperoxidase precipitated several radiolabeled bands from normal nucleated marrow cells. Most of these bands were markedly diminished or absent when excess cold myeloperoxidase was added before immunoprecipitation (Fig. 


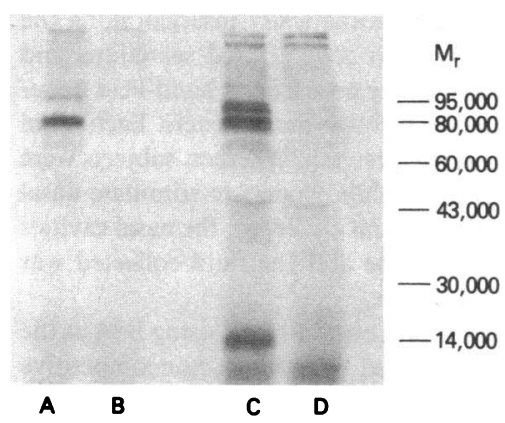

Figure 1. Immunoprecipitation of $\left[{ }^{35} \mathrm{~S}\right]-$ methionine-labeled normal nucleated marrow cells with antibody to lactoferrin or myeloperoxidase. Metabolically labeled normal nucleated marrow cell lysates were reacted with rabbit antihuman lactoferrin without (lane $A$ ) or with added cold lac-

toferrin (lane $B$ ) and immunoprecipitated. The same lysate preparation was also reacted with rabbit antihuman myeloperoxidase without (lane $C$ ) or with (lane $D$ ) added cold myeloperoxidase followed by immunoprecipitation.

1, lanes $C$ and $D$ ). Antimyeloperoxidase precipitated an identical set of myeloperoxidase-specific bands from patient M.S. nucleated marrow cells (Fig. 2, lanes $C$ and $D$ ). Some additional non-specific bands are seen with patient M.S. nucleated marrow cells that are not seen with normal nucleated marrow cells. The pattern of metabolically labeled myeloperoxidasespecific peptides precipitated by antimyeloperoxidase from normal nucleated marrow cells and patient M.S. nucleated marrow cells in this study is very similar to that previously reported with normal nucleated marrow cells (20). The bands at 82 and $90 \mathrm{kD}$ in lane $C$ of Figs. 1 and 2 are myeloperoxidase precursor peptides. In pulse-chase studies, it has been shown that complete processing of myeloperoxidase precursor peptides to mature peptide may take up to $20 \mathrm{~h}(21)$. Some fully processed 59-kD subunit of myeloperoxidase is detectable, but in Figs. 1 and 2 of this study it is artifactually displaced upward by the large amount of immunoglobulin brought down during the immunoprecipitation. Some fully processed small subunit of myeloperoxidase can be seen at $\sim 14 \mathrm{kD}$, although it is

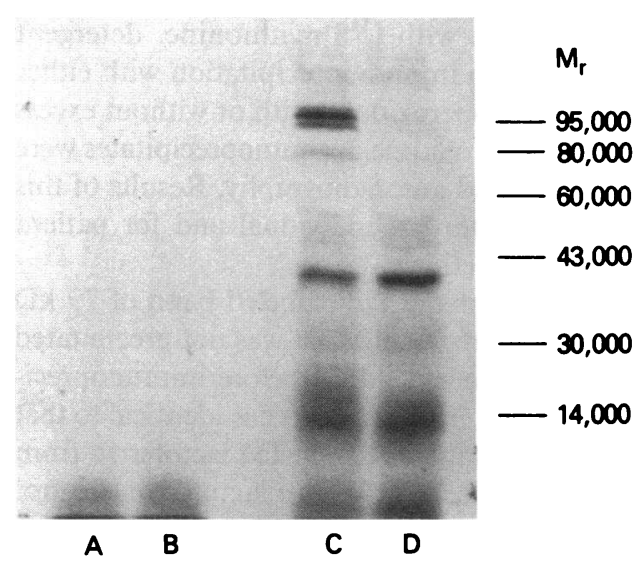

Figure 2. Immunoprecipitation of $\left[{ }^{35} S\right]$ methionine-labeled SGD nucleated marrow cells with antibody to lactoferrin or myeloperoxidase. Metabolically labeled SGD nucleated marrow cells lysates were reacted with rabbit antihuman lactoferrin without (lane $A$ ) or with (lane $B$ ) added cold lactoferrin and immunoprecipitated. The same lysate preparation was also reacted with rabbit anti-human myeloperoxidase without (lane $C$ ) or with (lane $D$ ) added cold myeloperoxidase followed by immunoprecipitation. somewhat obscured in the patient M.S. sample by nonspecifically labeled material.

These studies indicated that nucleated marrow cells from the SGD patient M.S. fail to synthesize immunochemically detectable lactoferrin peptides, but produce normal amounts of myeloperoxidase peptides. To determine whether this deficiency was secondary to decreased transcription of lactoferrin in nucleated marrow cells of SGD patients, a human lactoferrin cDNA probe was used for Northern blot analysis.

Lactoferrin and myeloperoxidase $m R N A$ in nucleated marrow cells. Total cellular RNA was prepared from nucleated marrow cells of two SGD patients, M.S. and M.F., and from nucleated marrow cells of two normal individuals. Total cellular RNA was also prepared from the light-density peripheral blood leukocytes of a patient with chronic myelogenous leukemia (predominantly myelocytes and metamyelocytes), and from uninduced cells of the HL-60 human promyelocytic cell line. Equal amounts of RNA from each of these sources were probed on Northern blots using either a human lactoferrin cDNA or a human myeloperoxidase cDNA.

Fig. $3 A$ and $B$ show Northern blots probed for either lactoferrin or myeloperoxidase mRNA transcripts, respectively. Uninduced HL-60 cell RNA has no detectable lactoferrin transcripts (Fig. $3 A$, lane $A$ ), whereas abundant myeloperoxidase mRNA is detected (Fig. $3 B$, lane $A$ ) as expected for a promyelocytic cell line. Lactoferrin mRNA is easily detected in RNA isolated from chronic myelogenous leukemia peripheral blood cells (predominantly myelocytes/metamyelocytes) (Fig. $3 A$, lane $B$ ). Myeloperoxidase mRNA transcripts are also present in these leukemia cells (Fig. $3 B$, lane $B$ ). Patient M.S. nucleated marrow cells contain only a trace amount of lactoferrin mRNA (Fig. $3 A$, lane $C$ ) when compared with that present in normal nucleated marrow cells (Fig. $3 A$, lane $D$ ). These lactoferrin transcripts, though markedly deficient in amount, are the same size as that seen in normal marrow. In contrast, patient M.S. nucleated marrow cells contain abundant myeloperoxidase mRNA (Fig. $3 B$, lane $C$ ) in an amount that is actually greater than that in the normal nucleated marrow cells examined in this experiment (Fig. $3 B$, lane $D$ ).

Northern blots of nucleated marrow cell RNA obtained from a second patient with SGD, M.F., which have been probed with lactoferrin cDNA or myeloperoxidase cDNA are
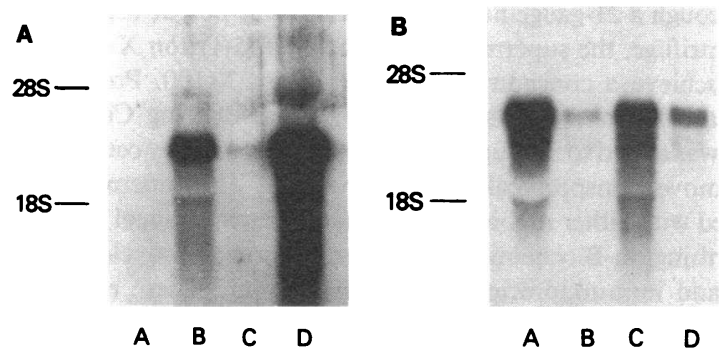

Figure 3. Northern blot analysis of SGD nucleated marrow cells (M.S). $20 \mu \mathrm{g}$ of total RNA were electrophoresed through an agaroseformaldehyde gel followed by blotting onto a nylon membrane. The blot was hybridized with a nick-translated lactoferrin cDNA $(A)$ or myeloperoxidase cDNA $(B)$. RNA samples in both panels included uninduced HL-60 cell RNA (lane $A$ ), chronic myelogenous leukemia peripheral blood leukocyte RNA (lane $B$ ), SGD nucleated marrow cell RNA obtained from patient M.S. (lane $C$ ), and normal nucleated marrow cell RNA (lane $D$ ). 
shown in Fig. 4, $A$ and $B$, respectively. In Fig. $4 A$, no detectable lactoferrin mRNA is seen in patient M.F. nucleated marrow cells (lane $C$ ) when compared with that present in normal nucleated marrow cells (lane $D$ ). With a long exposure of the autoradiograph, there is a very faint band in lane $C$ that may represent trace amounts of lactoferrin transcript from patient M.F. nucleated marrow cells (not shown). However, as shown in Fig. $4 B$, patient M.F. nucleated marrow cells contain myeloperoxidase mRNA transcripts (lane $C$ ) in an amount that is slightly less than that in the normal nucleated marrow cells examined in this experiment (lane $D$ ). The results of analysis of uninduced HL-60 RNA (lane $B$ in both panels) and chronic myelogenous leukemia peripheral leukocyte RNA (lane $A$ in both panels) are similar to that shown in Fig. 3.

Lactoferrin in nasal secretions. To determine whether the neutrophil lactoferrin deficiency in SGD represented an abnormality specific to myeloid cells, we evaluated lactoferrin in secretions from a patient with SGD. Baseline nasal secretions and secretions collected after gustatory provocation to stimulate the nasal serous glands were obtained from SGD patient, M.S., and from a normal individual (Table I). The amount of nasal lactoferrin secreted by M.S., as measured by percent of total protein, was at normal or greater than normal levels both before and after gustatory challenge.

Lactoferrin was detected after immunoblotting with antilactoferrin antisera in aliquots of nasal secretions and peripheral blood neutrophils from M.S. and a normal individual (Fig. 5). Lactoferrin protein in nasal secretions from M.S. (lanes $A$ and $B$ ) is indistinguishable in molecular weight from nasal secretion lactoferrin (lanes $C$ and $D$ ) and neutrophil lactoferrin (lane $F$ ) obtained from normal individuals. The abundance of lactoferrin in nasal secretions is in marked contrast to the absence of lactoferrin protein in peripheral neutrophils of patient M.S. (lane $E$ ).

Nasal lactoferrin and myeloid lactoferrin are identical in molecular weight and banding pattern on immunoblot and are likely the same protein. If they do represent the same protein product of a single gene, mRNA transcripts should also appear the same from tissue to tissue. Total cellular RNA obtained from normal nasal turbinates was probed with a myeloid cell lactoferrin cDNA (Fig. 6). Transcripts detected in nasal tur-
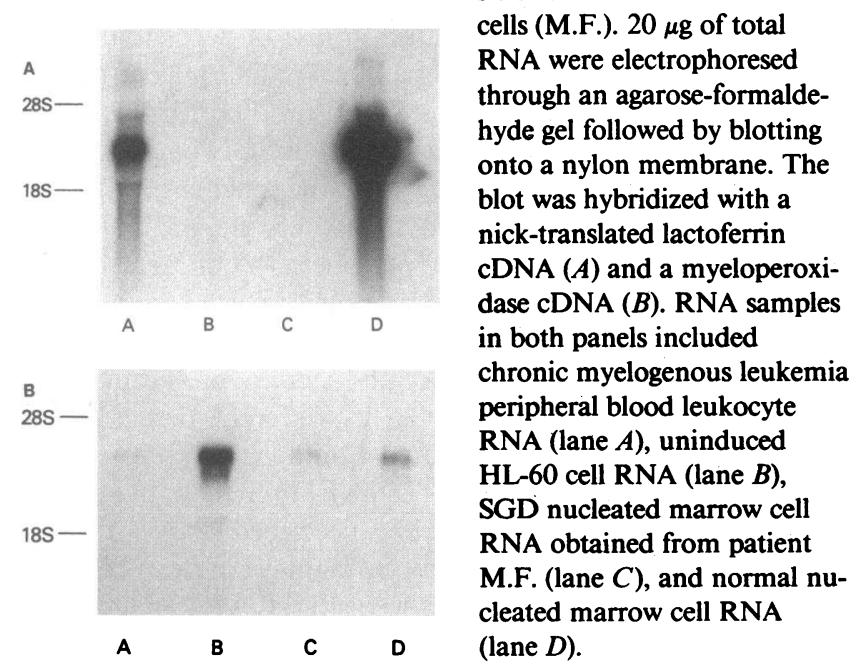
hyde gel followed by blotting onto a nylon membrane. The blot was hybridized with a nick-translated lactoferrin CDNA $(A)$ and a myeloperoxidase cDNA $(B)$. RNA samples in both panels included chronic myelogenous leukemia peripheral blood leukocyte RNA (lane $A$ ), uninduced HL-60 cell RNA (lane $B$ ), SGD nucleated marrow cell NA obtained from patien cleated marrow cell RNA (lane $D$ ).
Table I. Nasal Lavage Analyses: Total Protein and Lactoferrin

\begin{tabular}{|c|c|c|c|}
\hline & Total protein & Lactoferrin & Lactoferrin* \\
\hline & \multicolumn{2}{|c|}{$\mu g / m l$} & \% of total protein \\
\hline \multicolumn{4}{|l|}{ Patient M.S. } \\
\hline Right baseline & 400 & 28.0 & 7.0 \\
\hline Right challenge & 130 & 6.8 & 4.6 \\
\hline Left baseline & 170 & 2.4 & 1.8 \\
\hline Left challenge & 310 & 9.0 & 2.6 \\
\hline \multicolumn{4}{|l|}{ Normal subject } \\
\hline Right baseline & 190 & 1.8 & 1.0 \\
\hline Right challenge & 440 & 3.0 & 0.7 \\
\hline Left baseline & 110 & 0.8 & 0.7 \\
\hline Left challenge & 760 & 8.0 & 1.1 \\
\hline
\end{tabular}

Nasal lavage analysis. Nasal secretions before and after gustatory challenge were obtained from SGD patient M.S. and a normal individual. Total protein was measured by the Lowry method and lactoferrin was measured by a direct, noncompetitive ELISA.

* Lactoferrin \%, normal range $0-3 \%$ of total protein in nasal lavage fluid.

binate tissue were abundant (lanes $A$ and $B$ ) and of the same size as myeloid lactoferrin (lane $C$ ). Limited Southern blot analysis of genomic DNA from two SGD patients using the lactoferrin cDNA probe did not demonstrate any differences in restriction fragment lengths after digestion with several restriction endonucleases in comparison with normal genomic DNA (Fig. 7).

\section{Discussion}

Myeloid differentiation proceeds in an orderly fashion with stage specific expression of a variety of granule proteins. $\mathrm{Pa}$ tients with neutrophil SGD have an abnormality in myeloid differentiation that affects production of specific granules and their protein contents, as well as production of at least two additional proteins (gelatinase and defensins) found in other neutrophil granules (6). Lactoferrin, an important specific granule protein, is absent in the peripheral blood neutrophils of SGD patients. We have also demonstrated that these patients lack immunochemically detectable synthesis of lactoferrin in bone marrow myeloid precursors.

Our findings did not rule out the possibility that abnormal lactoferrin protein might be synthesized and very rapidly degraded in these patients. This is unlikely because several pro-
Figure 5. Immunoblot of nasal lavage fluid from a patient with SGD probed with rabbit antihuman LF. Nasal secretions from patient M.S. before (lane $A$ ) and after gustatory challenge (lane $B$ ). Nasal secretions from a normal before (lane $C$ ) and after gustatory challenge (lane $D$ ). Neutrophils $\left(2.5 \times 10^{6}\right.$ cells) from patient M.S. and a normal individual are in lane $E$ and lane $F$, respectively. 


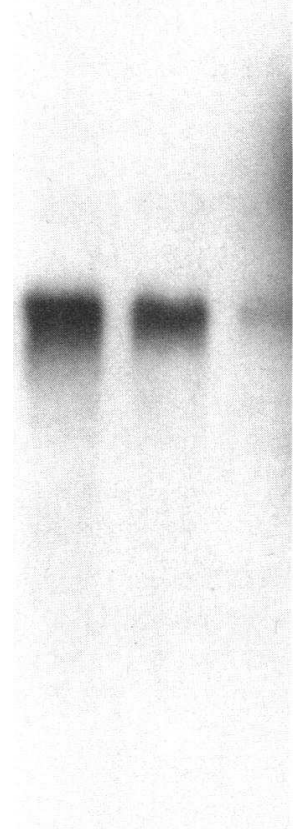

Figure 6. Northern blot of normal nasal turbinate RNA. $10 \mu \mathrm{g}$ of total cellular RNA isolated from normal nasal turbinate tissue was probed with nick-translated lactoferrin cDNA. Lanes $A$ and $B$ are samples from two normal individuals. Lane $C$, total cellular RNA isolated from the peripheral blood leukocytes of a A B $C$ mia.

teins are lacking from SGD neutrophils. We thought it unlikely that there would be mutations in the coding sequences producing abnormal proteins from all the genes whose products are known to be deficient in SGD. In addition to studying

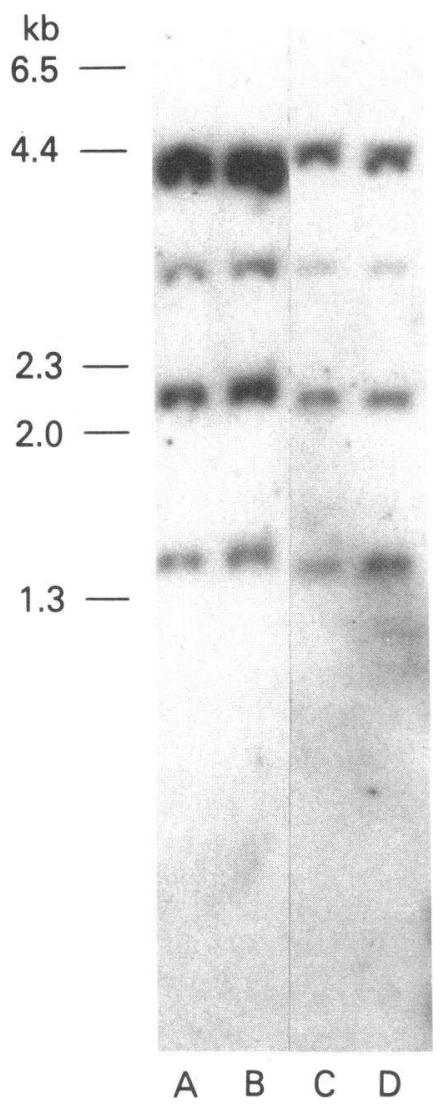

Figure 7. Southern blot analysis of SGD and normal genomic DNA. $10 \mu \mathrm{g}$ of DNA were digested with Eco RI and probed with a nick-translated lactoferrin cDNA. DNA isolated from SGD patients M.S. and M.F. are in lanes $A$ and $B$ Lanes $C$ and $D$ contain DNA isolated from two normal individuals. lactoferrin biosynthesis, we also examined production of a granule protein whose expression is unaffected in SGD. Myeloperoxidase, whose biosynthesis occurs at the promyelocyte stage of granulocytic maturation preceding lactoferrin biosynthesis, is normally expressed in these patients as we have shown in immunoprecipitation experiments. To evaluate the underlying defect in lactoferrin biosynthesis, we looked at transcription of lactoferrin in SGD patients and compared it with transcription of myeloperoxidase.

Failure of protein synthesis of selected granule proteins in myeloid cells of SGD patients could result from abnormal mRNA production or stability. Northern blotting experiments demonstrated that lactoferrin transcripts were present in only trace amounts in both lactoferrin deficient patients. These mRNA transcripts, although significantly diminished in abundance, were of the appropriate size. This suggests that the protein deficiency is secondary to a quantitative abnormality of RNA production rather than transcription of a mutant RNA that is unable to code for the normal protein. Detection of only trace amounts of lactoferrin mRNA on Northern blots does not rule out the possibility of production of unstable transcripts that are rapidly degraded. Nuclear run-on experiments that might have addressed this question more directly were not performed because of limited amounts of bone marrow obtainable from these patients. The presence of small amounts of lactoferrin transcripts in SGD nucleated marrow cells may result from inappropriate regulation of transcription by cis elements or trans-acting factors, abnormal nuclear processing of mRNAs and/or failure of the lactoferrin mRNA to be transported to the cytoplasm. Because we felt that our data supported our hypothesis that the deficiency of lactoferrin in SGD patients was secondary to an abnormality at the transcriptional level in myeloid cells, we examined lactoferrin production in other tissues. One SGD patient, unrelated to either of the two patients we have studied, has been previously reported to have normal lacrimal fluid lactoferrin (22). We evaluated one of our patients for lactoferrin secretion in nonmyeloid tissues.

Lactoferrin is secreted in a variety of exocrine fluids including lacrimal, nasal, parotid, and salivary gland secretions, breast milk, pancreatic juice, and semen. Recent localization of the human lactoferrin gene to chromosome 3 (23) substantiated previous evidence $(24,25)$ that lactoferrin protein present in normal neutrophils and lactoferrin secreted by the glandular epithelia of the various tissues listed above is the product of a single gene. Because of ease of accessibility, we chose to examine nasal secretions in one SGD patient for the presence of lactoferrin protein. As measured by ELISA, lactoferrin content in the nasal secretions of our SGD patient, M.S., was at normal levels after oral gustatory challenge. On immunoblot, nasal lactoferrin protein is indistinguishable from the lactoferrin found in normal peripheral blood neutrophils. Lactoferrin transcripts detected in normal nasal turbinate tissue, which has abundant nasal secretory glands, were of the same size as myeloid cell transcripts, thereby providing more evidence that lactoferrin secreted by different tissues is the product of a single gene. Limited Southern blotting experiments probing normal genomic DNA from SGD patients with the same lactoferrin cDNA probe described above did not reveal any differences in restriction fragment pattern between normal and SGD DNA. From these studies we conclude that the SGD patients have a lactoferrin gene with an intact protein 
coding sequence that is normally expressed in a nonmyeloid tissue.

The defect in expression of the lactoferrin gene in SGD is tissue specific and is associated with normal levels of lactoferrin in nasal secretions in our patient M.S. (and also in this patient's lacrimal, parotid, and submandibular gland secretions; Raphael, G. D., unpublished observations). In myeloid tissues, the defect in expression of this protein is accompanied by a deficiency of mRNA transcripts, suggesting that regulation of protein synthesis in these cells is at the level of mRNA production. Because lactoferrin deficiency in SGD is associated with deficiency of several other granule proteins, we postulate that it represents a stage-specific failure of normal myeloid maturation. It is possible that an abnormality in regulation of transcription of the lactoferrin gene may extend to the other affected proteins and these affected secretory proteins may represent a cassette of genes whose expression is regulated coordinately during the appropriate stage of maturation. Understanding the underlying defect in SGD may provide important insights into regulation of myeloid maturation.

\section{Acknowledgments}

We thank Dr. William Nauseef for allowing us to use his myeloperoxidase cDNA and Dr. Thomas A. Rado for sharing his lactoferrin cDNA clone. The helpful assistance of Dr. Jim Baraniuk and Dr. Marco Merida in obtaining nasal turbinate specimens is gratefully acknowledged. We would also like to recognize the excellent technical assistance of Cynthia Burch-Whitman and Lee Tiffany. Helpful discussions with Dr. Elise Feingold were greatly appreciated.

This work was supported in part by a Swebilius Cancer Research Award (to K. J. Lomax), National Institutes of Health grants HL-24385 and HL-28076 (to E. J. Benz, Jr.), and El-20065 and HL-31963 (to L. A. Boxer).

\section{References}

1. Gallin, J. I. 1985. Neutrophil specific granule deficiency. Annu. Rev. Med. 36:263-274.

2. Falloon, J., and J. I. Gallin. 1986. Neutrophil granules in health and disease. J. Allergy Clin. Immunol. 77:653-662.

3. Gallin, J. I., M. P. Fletcher, B. E. Seligmann, S. Hoffstein, K. Cehrs, and N. Mounessa. 1982. Human neutrophil-specific granule deficiency: a model to assess the role of neutrophil-specific granules in the evolution of the inflammatory response. Blood. 59:1317-1329.

4. Borregaard, N., L. A. Boxer, J. E. Smolen, and A. I. Tauber. 1985. Anomalous neutrophil granule distribution in a patient with lactoferrin deficiency. Am. J. Hematol. 18:225-260.

5. Ohno, Y., B. E. Seligmann, and J. I. Gallin. 1985. Cytochrome b translocation to human neutrophil plasma membranes and superoxide release. J. Biol. Chem. 260:2409-2414.

6. Ganz, T., J. A. Metcalf, J. I. Gallin, L. A. Boxer, and R. I. Lehrer. 1988. Microbicidal/cytotoxic proteins of neutrophils are deficient in two disorders: Chediak-Higashi syndrome and "specific" granule deficiency. J. Clin. Invest. 82:552-556.

7. Petty, H. R., J. W. Francis, R. F. Todd III, P. Petrequin, and L. A. Boxer. 1987. Neutrophil C3bi receptors: formation of membrane clusters during cell triggering requires intracellular granules. $J$. Cell Phys. 133:235-242.

8. Breton-Gorius, J., D. Y. Mason, D. Bruiot, J. L. Vilde, and C.
Griscelli. 1980. Lactoferrin deficiency as a consequence of a lack of specific granule in neutrophils from a patient with recurrent infections. Am. J. Pathol. 99:413-419.

9. Boxer, L. A., T. D. Coates, R. A. Haak, J. B. Wolach, S. Hoffstein, and R. L. Baehner. 1982. Lactoferrin deficiency associated with altered granulocyte function. N. Engl. J. Med. 307:404-409.

10. Chirgwin, J. M., A. E. Przybyla, J. MacDonald, and W. J. Rutter. 1979. Isolation of biologically active ribonucleic acid from sources enriched in ribonuclease. Biochemistry. 18:5294-5299.

11. Gallagher, R., S. Collins, J. Trujillo, K. McCredie, M. Ahearn, S. Tsai, R. Metzgar, G. Aulakh, R. Ting, F. Ruscetti, and R. Gallo. 1979. Characterization of the continuous, differentiating myeloid cell line (HL-60) from a patient with acute promyelocytic leukemia. Blood. 54:713-733.

12. Rado, T. A., X. Wei, and E. J. Benz, Jr. 1987. Isolation of lactoferrin cDNA from a human myeloid library and expression of mRNA during normal and leukemic myelopoesis. Blood. 70:989-993.

13. Johnson, K. R., W. M. Nauseef, A. Care, M. J. Wheelock, S. Shane, S. Hudson, H. P. Koeffler, M. Selsted, C. Miller, and G. Rovera. 1987. Characterization of cDNA clones for human myeloperoxidase: predicted amino acid sequence and evidence for multiple mRNA species. Nucleic Acids Res. 15:2013-2028.

14. Nauseef, W. M., R. K. Root, and H. L. Malech. 1983. Biochemical and immunologic analysis of hereditary myeloperoxidase deficiency. J. Clin. Invest. 71:1297-1307.

15. Lowry, O. L., N. J. Rosebrough, A. L. Farr, and R. J. Randall. 1951. Protein measurement with the Folin phenol reagent. J. Biol. Chem. 193:265-275.

16. White, M. V., and M. A. Kaliner. 1987. Neutrophils and mast cells, I. Human neutrophil-derived histamine-releasing activity. J. Immunol. 139:1624-1630.

17. Gardner, J. P., D. A. Melnick, and H. L. Malech. 1986. Characterization of the formyl peptide chemotactic receptor appearing at the phagocytic cell surface after exposure to phorbol myristate acetate. $J$. Immunol. 136:1400-1405.

18. Gierschik, P., J. Falloon, G. Milligan, M. Pines, J. I. Gallin, and A. M. Spiegel. 1986. Immunochemical evidence for a novel pertussis toxin substrate in human neutrophils. J. Biol. Chem. 261:8058-8062.

19. Rado, T. A., J. Bollekens, G. St. Laurent, L. Parker, and E. J. Benz, Jr. 1984. Lactoferrin biosynthesis during granulocytopoesis. Blood. 64:1103-1109.

20. Koeffler, H. P., J. Ranyard, and M. Pertchek. 1985. Myeloperoxidase: Its structure and expression during myeloid differentiation. Blood. 65:484-491.

21. Olsson, I., M. Lantz, A.-M. Persson, and K. Arnljots. 1988. Biosynthesis and processing of lactoferrin in bone marrow cells, a comparison with processing of myeloperoxidase. Blood. 71:441-447.

22. Ambruso, D. R., S. Masataka, H. Nishiyama, A. Kubo, A. Komiyama, and R. H. Allen. 1984. Defective bactericidal activity and absence of specific granules in neutrophils from a patient with recurrent bacterial infections. J. Clin. Immunol. 4:23-30.

23. Teng, C. T., B. T. Pentecost, A. Marshall, A. Solomon, B. H. Bowman, P. A. Lalley, and S. L. Naylor. 1987. Assignment of the lactotransferrin gene to human chromosome 3 and to mouse chromosome 9. Somatic Cell Mol. Genet. 13:689-693.

24. Moguilevsky, N., L. A. Retegui, and P. L. Masson. 1985. Comparison of human lactoferrins from milk and neutrophilic leucocytes. Biochem. J. 229:353-359.

25. Broxmeyer, H. E., D. C. Bicknell, S. Gillis, E. L. Harris, L. M. Pelus, and G. W. Sledge. 1986. Lactoferrin: affinity purification from human milk and polymorphonuclear neutrophils using monoclonal antibody (II 2C) to human lactoferrin, development of an immunoradiometric assay using II $2 \mathrm{C}$, and myelopoetic regulation and receptor binding characteristics. Blood Cells. 11:429-446. 